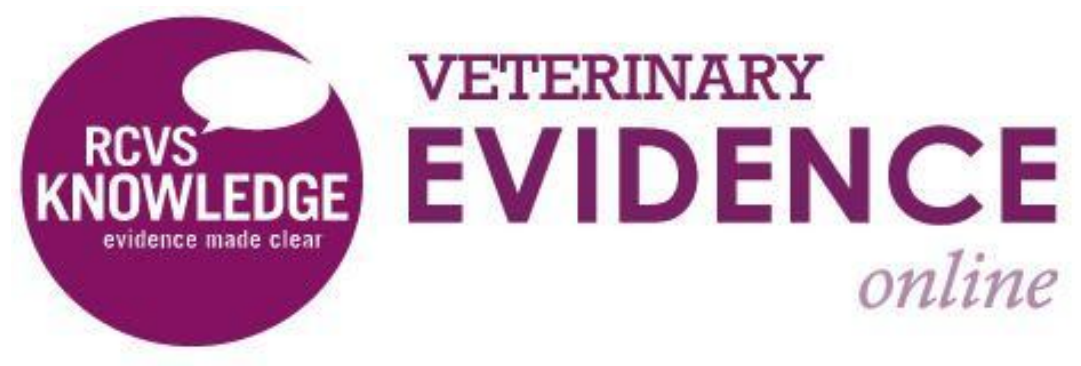

\title{
The Use of Mobile Devices and Online Services by German Veterinary Students
}

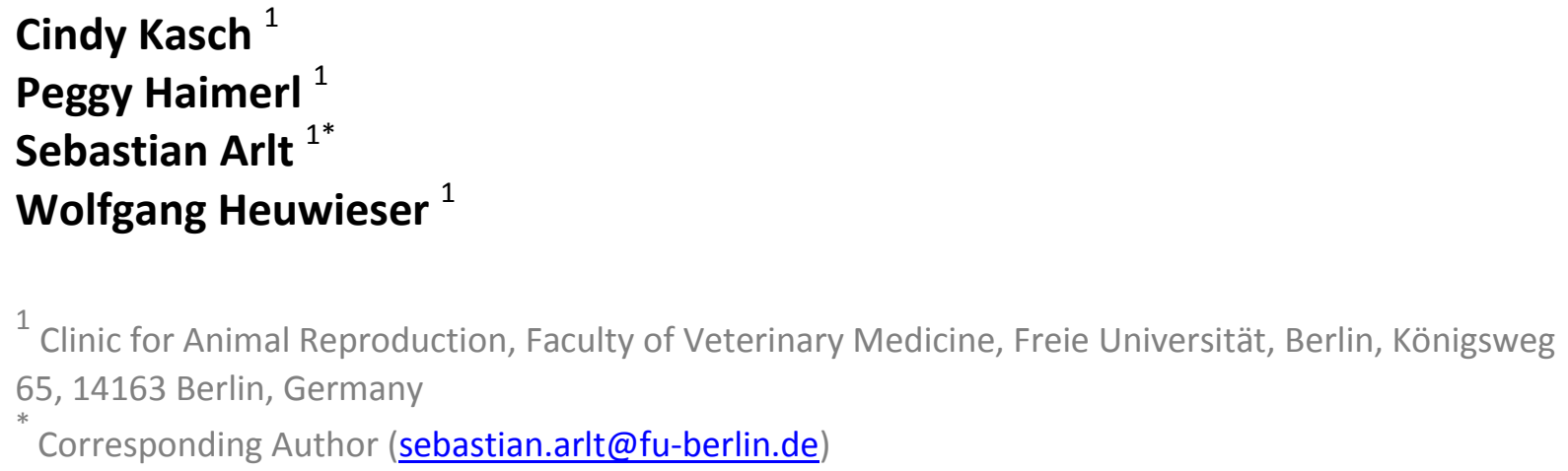

${ }^{1}$ Clinic for Animal Reproduction, Faculty of Veterinary Medicine, Freie Universität, Berlin, Königsweg 65, 14163 Berlin, Germany

Corresponding Author (sebastian.arlt@fu-berlin.de)

ISSN: 2396-9776

Published: 4 July 2016

in: Vol 1, Issue 3

DOI: http://dx.doi.org/10.18849/ve.v1i3.41

Reviewed by: Erik Fausak (MSLIS, MA, CVT, LVT, RLAT) 
Objective: The research question of our study was to determine the adoption and use of mobile devices and online services by veterinary students.

Background: New technologies support learning, communication and information transfer during the preprofessional years and the professional lifetime. Hence, mobile devices may also be a feasible tool for information access for the practitioner at any place and any time, and consequently may support better informed clinical decision making.

Evidentiary value: We conducted a survey among 124 German veterinary medical students in their third year with a median age of 23.0 years.

Methods: The survey was conducted during a lecture and contained 10 questions with preset answers to be ticked and a free text comment section. Participation was voluntary and data processing was performed anonymously.

Results: According to the answers of surveyed third year students $84.7 \%$ used a smartphone as a mobile device. The vast majority of the veterinary students used Google, Facebook and WhatsApp besides other applications.

Conclusion: Most students are familiar with mobile devices and the use of social media and information tools. Thus, new learning strategies could be developed and applied that encompass mobile online learning and information access. These strategies could help to better address different learning types, provide sufficient interactivity and feedback and enable veterinarians to seek and share information via the internet. However, despite promising results reporting a positive educational effect, these perceptions need to be validated in further research. In addition, it should be assessed in future surveys if veterinarians would use mobile online access to scientific data or Knowledge Summaries for better informed decision making in practice.

Application: Veterinary students, and thus the next generation of veterinary practitioners, are using mobile devices to a high extent. This paves the way to refine existing and to develop new education strategies. New information tools for mobile devices may help veterinarians to seek and share information. In addition, it might be worthwhile to teach veterinary students and practitioners how to search for and appraise online scientific information.

INTRODUCTION

Students frequently use mobile devices for everyday activities such as talking and texting (Applegate, 2010). In 2013, more than 60 billion instant-messages and SMS were communicated every day (Informa, 2013), mostly by teenagers and adolescents (Goodarzi, 2012; Herman, 2007). It is expected that this amount will be doubled by 2017 (Juniper Research; eMarketer, 2013). The rapid development of new communication technologies also has a major influence on veterinary education (Short, 2002; Valliyate, 2012). Already now, veterinary teaching has profited considerably from advances in information communication technology (Simões, 2010). For example, computerised testing has made significant inroads into veterinary education (Folk, 2006). Also, learning management platforms such as Blackboard (www.blackboard.com), which enable lecturers to provide teaching materials online, and information tools like wiki systems (Kolski, et al. 2015) represent such a technological advance. A well-known advantage of the integration of new technology into education is that it enables students to study independently to location and time (Short, 2002). 
Furthermore, technological advance allows the usage of virtual patients as an educational aid, as suggested by Trace et al. (2012) or Schaper et al. (2011). The most important prerequisite for this type of communication is the availability and actual use of adequate technology. According to Cole-Lewis and Kershaw (2010), across the world (in both developing and developed countries) more and more people are gaining access to the Internet via mobile phones. Consequently, more and more people do have access to current medical knowledge. Since this potentially facilitates clinical decision making, it in turn supports the implementation of evidence-based veterinary medicine. However, this means that students need to gain competence in information search and retrieval via the Internet. Little research has been published on how veterinary students actually use mobile devices (Gikas and Grant, 2013). Hence, the research question of our study was to determine adoption and use of mobile devices and online services by veterinary students.

\section{METHODS \& MATERIALS}

In March 2014, we conducted a survey among veterinary medical students in their third year. In this term of education the students participate in lectures and seminars offered by the Clinic for Animal Reproduction, Berlin, Germany. At the beginning of a lecture we asked the students to participate in the survey. We developed the questionnaire according to statements and suggestions made by students that participated in earlier courses and seminars. Participation was voluntary. Students declared informed consent by completing the survey. The project was reviewed and approved by the Ethical Commission of the Charite Hospital associated with Freie Universität Berlin (EA 1/126/16).

The students had 15 minutes to answer the questionnaire which contained 10 questions with preset answers to be ticked and a free text comment section (Figure 1). After a short introduction to the study and demographic questions (i.e. age, semester, and gender) three questions addressed the use of mobile devices. The second part dealt with the students' habits and preferences concerning the application of mobile devices. We performed descriptive statistical analysis anonymously using the statistic program SPSS for Windows (Version 22.0; SPSS Inc., Munich, Germany). We performed frequency analysis on the obtained quantitative data. Furthermore, we used cross tables to analyse the students' answers considering both genders. Finally, we analysed the quantitative data using the two tailed Fisher's Exact Test and the Pearson-Chi ${ }^{2}$-Test. We set the significance level as $\alpha=0.05$. For a statistical analysis of free text comments we considered them as qualitative data.

\section{RESULTS}

In total, 124 of 130 students (101 female and 22 male) completed the questionnaire. One participant did not specify gender, age or semester. Median age of participating students was 23.0 (IQR 22.0 - 25.0). The majority of the students (84.7\%) stated to use a smartphone as a mobile device (Table 1 ).

About one fourth of the students (23.4\%) additionally utilised tablets, while $8.1 \%$ employed a laptop in addition. The given answers revealed that, regarding operating systems, students preferred IOS (41.1\%) and Android (44.3\%). The majority of students (78.2\%) stated to have an Internet flat rate for their mobile device. Concerning online services used via mobile devices, most of the participating students $(78.2 \%)$ used Google. Moreover, $62.9 \%$ of the students accessed the e-learning platform of the FU Berlin (Blackboard) via mobile devices. Similarly, the majority of students (54.0\%) frequently used Google maps. Most of the respondents 
(61.3\%) used online dictionaries occasionally while, respectively, $50.8 \%$ and $42.7 \%$ stated to consult the information platform Wikipedia often and occasionally. In addition to the suggested online services, six students (4.8\%) added further options (e.g. veterinary dictionary DocCheck) as free text comments. While 15 students (12.1\%) reported to have a Quick response (QR) - code reader, 18 stated to use such a tool, either often ( $n=1$ ) or occasionally ( $n=17$ ). With $74.2 \%$ and $70.2 \%$, respectively, WhatsApp and Facebook turned out to be the most frequently used social media services (Table 2 ).

In line with that, $44.3 \%$ of the students referred to WhatsApp as their favourite application software. This was also supported by comments in the free text comment section. Moreover, more than half of the students (53.2\%) occasionally used Skype; a software allowing free instant messaging and voice or video calls. On the contrary, only few students indicated a frequent or occasional use of social media like Viber (3.2\%), Talk $(1.6 \%)$, Twitter $(0.8 \%)$, Instagram $(8.9 \%)$, Telegram $(8.9 \%)$ or Snapchat $(2.4 \%)$. More than one-third of the students spent 2 to 4 hours per day online via mobile devices. The majority of the students $(68.5 \%)$ indicated that they answer incoming messages only when they find time to do this. Veterinary online applications wished for by the responding students included a "laboratory data app" (4.8\%) or learning apps (4.8\%), that were not further specified.

DISCUSSION

Mobile learning and information retrieval has been growing internationally in visibility and significance (Traxler, 2007, 2010, 2012). Therefore, we wanted to investigate if German students of veterinary medicine have adopted the use of mobile devices as well. Current mobile devices are designed to allow users to enter and access data like contacts and memos, to send and receive messages, to view documents and pictures, or to access the web (Kukulska-Hulme, 2005). In 2013, 96\% of people in Germany aged between 12 and 19 owned a smartphone (Kutscher, 2014). In our survey, the share of veterinary students who stated to use a smartphone regularly resembled those findings (84.7\%). Moreover, the fact that the majority of the participants (78.2\%) had an internet flat rate was in accordance with the findings of Wallace et al. (2012). The finding that the vast majority have mobile access to the internet indicates that online professional tools designed for mobile devices have a great potential to reach the majority of veterinary students and also presumably a growing proportion of practitioners and clinicians in Germany.

Regarding online education, the concept of 'anytime' and 'anyplace' offered by mobile learning may be an important pedagogical aspect (Bidin and Ziden, 2013). As emphasised by Smith (2003), e-learning should accommodate different learning styles and provide sufficient interactivity, testing, and feedback to engage the user. Personalised learning can recognise diversity and individuality of the students and account for different learning styles and approaches (Traxler, 2007). One way this can be accomplished is by an assortment of tools that learners can combine to best suit their individual learning styles to increase their academic success (Rodriguez, 2011). A more recent interview-based survey showed that $90 \%$ of the participants used mobile computing devices and that this usage was believed to have a positive educational effect (Wallace, et al. 2012). Since an interview allows face to face communication and immediate feed-back for both interviewer and interviewee, such an approach might be beneficial for further research in this area.

According to our findings, the vast majority of the veterinary students used the search engine Google (96.7\%), either frequently (78.2\%) or occasionally (18.5\%). Those data deviate from Wallace et al. (2012), who found that $50 \%$ of those participating in their survey stated to use Google. However, their study was conducted in 2012 and the growing popularity of Google might at least partly account for these differences. Furthermore, the authors did not only interview students in their survey, but also residents and members of the faculty. Hence, as shown previously we can assume that the resulting higher average age explains for the lower usage 
of online media (Wolff, 2006) like the search engine (Pew Research Center. n.d., 2011). Those two aspects might also explain why only $15 \%$ of their participants used the encyclopedia Wikipedia, whereas more than half of our participants $(50.8 \%)$ stated to do so. Since Wikipedia is not specific for veterinary medicine, a wikisystem designed for veterinary purposes may be advantageous (Kolski, et al. 2015). A special issue connected with this topic is the quality of provided information. It is essential to train students to critically assess information, especially if it is found on webpages or wiki systems with unknown expertise of the author. Clinical decisions based on false, incomplete or outdated data may be highly detrimental for the health and well-being of the animals.

QR-Code readers, a mobile device tool enabling the scanning of bar codes (Lorenzi, et al. 2014, Ramsden, 2008), were not popular according to our survey. QR-Codes enable a quick uptake of data in a compact fashion (Lorenzi, et al. 2014) or visiting a specific website without typing the address of the webpage. With regard to our survey, only $12.1 \%$ of the veterinary students used such a tool. These data correspond with earlier findings where only $2 \%$ of students had scanned a QR code with their device (Ramsden, 2008). Different promising recommendations for the use of QR-Codes within a lecture or course have been published. For example, students may easily get access to handouts, additional online presentations or feedback questions by scanning a QR-Code integrated into a presentation (Ramsden, 2008). Another application may be a direct link to standard operation procedures or specific additional information. Surprisingly, in our survey, there were more students stating to use QR-Codes (14.5\%) than having installed a QR code reader on their device. This discrepancy may indicate that some students did not read the question carefully. On the other hand, some students may have used this tool with the device of someone else or have uninstalled the reader.

A majority of the participants stated to frequently use Facebook (70.2\%) or WhatsApp (74.2\%). Both applications are reported to rank among the most popular ones used by young people in Germany (Kutscher, 2014; Roblyer, 2010). Also, 44.3\% of the students referred to WhatsApp as their favourite application software. WhatsApp enables users to send and receive text messages, images, audio and video files (Church and de Oliveira, 2013). Membership of online social networks has recently exploded at an exponential rate (Cheung, et al. 2010). According to Facebook reports, they had 1.44 billion users in the first three months of 2015, out of which 1.25 billion additionally and 581 million exclusively used mobile access (Facebook, 2015a, Facebook, 2015b). As reported by Pempek et al. (2009), students use Facebook approximately 30 min per day for study purposes. Via WhatsApp, more than 10 billion messages are sent per day and it is one of the most popular paid Apps across all mobile platforms (Church and de Oliveira, 2013). Concerning possible benefits of integrating online tools into education, Greenhow (2011) emphasised that social utilities do not only have a social effect, but can also have a positive impact on learning outcomes. However, this potential positive impact on learning success should be assessed in future research, especially since current information of practical relevance is increasingly shared via social media. By allowing an almost real-time interaction between students and instructors (Gikas and Grant, 2013), the integration of social tools may promote a more student-centred course (Greenhow, 2011). This live contact with others also allows direct conversations on a topic or issue (Gikas and Grant, 2013; Traxler, 2007), and by that may support the concept of collective learning and critical discussion (Levy, 2001). Furthermore, using the highly interactive knowledge sharing features of a virtual community can increase the student's learning motivation (Wasko and Faraj, 2005). According to a study by Wu et al. (2014), the diverse resources provided in virtual communities promoted critical thinking, problem analysis, and problem-solving skills of the researched nursing students. With regard to our survey, more than one-third of the students (36.3\%) spent two to four hours per day online with their mobile devices.

Some students stated that they would like to have a "laboratory data App" or other learning apps. The reason that only a small proportion of surveyed students suggested new tools may be due to the fact that few Apps already exist for veterinary purposes or that they are rarely used. Therefore, the students may not be aware of the possibilities such Apps may provide. This issue should be surveyed in a future project. We assume that the development of such tools, together with the involvement of students in the creative process, might foster their motivation and consequently increase their learning outcome (Bidin and Ziden, 2013), and at the same time increase the number of applicable learning and information tools. Overall, the use of the new technology 
may offer the possibility to consider new learning strategies (Bidin and Ziden, 2013; Short, 2002). However, studies which attempted to systematically assess the learning success of online and mobile teaching compared to the traditional approach have hardly been published. In addition, it has to be assessed if information tools would be accepted and used by practitioners. However, it sounds plausible that a practitioner may see benefits in an App that provides dosages or other information and is accessible on-site by a mobile phone while examining the patient. In addition, online tools offering current and easily accessible research syntheses may support transfer of new knowledge into practice and enable an efficient information search. In that regard, it might be worthwhile to train students in how to search and appraise online scientific information.

In spite of various interesting findings, we are aware of the limitations of our survey. The small number of male students, for example, caused an uneven gender distribution (22 male vs. 101 female). Furthermore, only veterinary students of the Free University of Berlin in their third year were included. Also, the fact that many questions offered the possibility to tick more than one answer may have led to bias. However, the objective of the study was to research the distribution and use of mobile devices, and a survey is likely to be one of the best methods to acquire valuable and evaluable data. Considering that objective, we inevitably had to face the uneven gender distribution typical for veterinary schools worldwide (Kostelnik, et al. 2010).

To sum it up, mobile devices have found their way into the everyday life of veterinary students. As shown in our survey students valued the new possibilities of online communication. Hence, the development of online learning tools and information platforms meeting the specific demands of veterinary medicine should be promoted. However, some authors criticise that mobile learning should only represent a supplement since it might imply learning across contexts and at different times, resulting in fragmented knowledge and incomplete schemata (Gikas and Grant, 2013; Tella, 2003; Traxler, 2010). Overall, the integration of mobile devices in education may assist most students in their learning (Gikas and Grant, 2013).

In conclusion, veterinary students (equivalent to the next generation of veterinary practitioners) are using mobile devices to a high extent. This paves the way to refine already existing and to develop new education and information tools for mobile devices. However, conflicts may arise since not every teacher and student is able or willing to handle mobile devices or other new technologies (Gikas and Grant, 2013). Hence, augmenting the importance of new technologies within education might lead to isolation of those not having access to mobile devices. Most importantly, although it is difficult to evaluate mobile learning (Traxler, 2007), further studies are warranted to examine the learning success. In addition, courses at universities should address skills in searching and assessing online information. Finally, it should be assessed in future surveys if veterinarians would use mobile online access to scientific data or Knowledge Summaries for better informed decision making in practice.

\section{CONFLICT OF INTEREST}

Acknowledgments: The authors gratefully thank the participants of the survey. In addition, we thank the students that provided statements and suggestions for the design of the survey. Also, many thanks go to Özlem Cigdem, a student of integrated natural sciences at the Freie Universität, who stayed with us for two weeks in terms of a work practice for helping to develop the questionnaire.

Competing interests: None to declare. The manuscript, or parts of it, have not been and will not be submitted elsewhere for publication. None of the authors have any financial or personal relationships that could inappropriately influence or bias the content of the paper. 
1. Applegate, JS. (2010) The Role of Mobile Electronic Devices in Radiographer Education. Radiologic Technology, 82 (2), pp. 124-31.

2. Bidin, S. and Ziden, AA. (2013) Adoption and Application of Mobile Learning in the Education Industry. Procedia - Social and Behavioural Sciences, 90 pp. 720-729.

3. Cheung, CMK. Pui-Yee, Chiu and Lee, MKO. (2010) Online Social Networks: Why Do Students Use Facebook? Computers in Human Behavior, 27 (4), pp. 1337-43.

http://dx.doi.org/10.1016/i.chb.2010.07.028

4. Church, K. and de Oliveira, R. (2013) What's up with Whatsapp?: Comparing Mobile Instant Messaging Behaviors with Traditional SMS. In: MobileHCl '13 15th International Conference on Human-Computer Interaction with Mobile Devices and Services Munich, Germany: Association for Computing Maschinery; 2013. pp. 352-61.

5. Cole-Lewis, H. and Kershaw, T. (2010) Text Messaging as a Tool for Behavior Change in Disease Prevention and Management. Epidemiologic Reviews, 32 (1), pp. 56-69.

http://dx.doi.org/10.1093/epirev/mxq004

6. Facebook. (2015a) Facebook Q1 2015 Results. [online] Available from: http://files.shareholder.com/downloads/AMDA-NJ5DZ/484348833x0x822961/FD718A09-C312-46059A17-1D6EF07BDD5A/FB_Q115EarningsSlides.pdf. [Accessed 22 April 2015].

7. Facebook. (2015b). Facebook Reports First Quarter 2015 Results. [online] Available from: http://investor.fb.com/releasedetail.cfm?ReleaselD=908022. [Accessed April 22, 2015].

8. Folk, LC. March, JZ. and Hurst, RD. (2006) A Comparison of Linear, Fixed-Form Computer-Based Testing versus Traditional Paper-And-Pencil-Format Testing in Veterinary Medical Education. Journal of Veterinary Medical Education, 33 (3), pp. 455-64. http://dx.doi.org/10.3138/jvme.33.3.455

9. Gikas, J. and Grant, MM. (2013) Mobile Computing Devices in Higher Education: Student Perspectives on Learning with Cellphones, Smartphones \& Social Media. The Internet and Higher Education, 19, pp. 18-26. http://dx.doi.org/10.1016/j.iheduc.2013.06.002

10. Goodarzi, M. et al. (2012) Impact of Distance Education via Mobile Phone Text Messaging on Knowledge, Attitude, Practice and Self Efficacy of Patients with Type 2 Diabetes Mellitus in Iran. Journal of Diabetes \& Metabolic Disorders, 11 (1), p. 10. http://dx.doi.org/10.1186/2251-6581-11$\underline{10}$

11. Greenhow, C. (2011) Youth, Learning, and Social Media. Journal of Educational Computing Research, 45 (2), pp. 139-46. http://dx.doi.org/10.2190/EC.45.2.a

12. Herman, S. (2007) SMS Reference: Keeping up with Your Clients. The Electronic Library, 25 (4), pp. 4018. http://dx.doi.org/10.1108/02640470710779817

13. Informa nd. (2013) Versand, von. Instant-Messaging-Nachrichten und SMS weltweit 2011 und 2012 und Prognose für 2013 (in Mrd. pro Tag). [online] Available from: http://de.statista.com/statistik/daten/studie/258398/umfrage/prognose-der-instant-messagingnachrichten-vs-sms-weltweit/. [Accessed April 22nd 2016].

14. Juniper Research; eMarketer. (2013) Mobile Message Traffic Worldwide in 2012 and 2017 (in Trillions). [online] Available from: http://www.statista.com/statistics/262005/mobile-message-trafficworldwide/. [Accessed April 22nd 2016].

15. Kostelnik, K. et al. (2010) Feminization of the Veterinary Profession and the Shortage of Food Supply 
Veterinarians. Tierärztliche Praxis, 38 (3), pp. 156-64.

16. Kolski, D. Heuwieser, W. and Arlt, S. (2015) Use and Future of Wiki Systems in Veterinary Education?-A Survey of Lecturers in German-Speaking Countries. Gesellschaft für Medizinische Ausbildung, 32 (5), Doc54. http://dx.doi.org/10.3205/zma000996

17. Kukulska-Hulme, A. (2005) Mobile Usability and User Experience In: Kukulska-Hulme A, Traxler J, eds. Mobile Learning - A Handbook for Educators and Trainers. Abingdon, UK: Routledge, pp. 45-7.

18. Kutscher, N. (2014) Apps, Facebook, Onlineberatung... Sozial Extra, 38 (4), pp. 39-

41. http://dx.doi.org/10.1007/s12054-014-0093-y

19. Levy, P. (2001) Cyberculture. Minneapolis: University of Minnesota Press, pp. 151-154.

20. Lorenzi, D. et al. (2014) Enhancing the Government Service Experience through QR Codes on Mobile Platforms. Government Information Quarterly, 31 (1), pp. 6-16.

http://dx.doi.org/10.1016/i.giq.2013.05.025

21. Pempek, TA. Yermolayeva, YA. and Calvert, SL. (2009) College Students' Social Networking Experiences on Facebook. Journal of Applied Developmental Psychology, 30 (3), pp. 227-38.

http://dx.doi.org/10.1016/j.appdev.2008.12.010

22. Pew Research Center. n.d. (2011) Percentage of U.S. Internet Users Accessing Search Engines as of May 2011, by Age Group. [online] Available from: http://www.statista.com/statistics/274190/ussearch-engine-usage-by-age-group/. [Accessed April 22nd 2016].

23. Ramsden, A. (2008) The Use of QR Codes in Education: A Getting Started Guide for Academics. [online] Available from: http://opus.bath.ac.uk/11408/1/getting_started_with_QR_Codes.pdf. [Accessed April 22nd 2016]. pp. 1-9.

24. Roblyer, MD. et al. (2010) Findings on Facebook in Higher Education: A Comparison of College Faculty and Student Uses and Perceptions of Social Networking Sites. The Internet and Higher Education, 13

(3), pp. 134-40. http://dx.doi.org/10.1016/j.iheduc.2010.03.002

25. Rodriguez, JE. (2011) Social Media Use in Higher Education: Key Areas to Consider for Educators. Journal of Online Learning and Teaching, 7 (4), pp. 539-50.

26. Schaper, E. et al. (2011) Case-Based Assessment in Veterinary Medicine - Searching for Alternatives to Multiple Choice Questions. Tierärztliche Umschau, 66 (6), pp. 261-8.

27. Short, N. (2002) The Use of Information and Communication Technology in Veterinary Education. Research in Veterinary Science, 72 (1), pp. 1-6. http://dx.doi.org/10.1053/rvsc.2001.0531.

28. Simões, JCC. (2010) Information Communication Technology Applied to Veterinary Education in Early XXI Century. Veterinary.Com, 3 (1), pp. 1-29.

29. Smith, RD. (2003) The Application of Information Technology in the Teaching of Veterinary Epidemiology and Public Health. Journal of Veterinary Medical Education, 30 (4), pp. 344-50. http://dx.doi.org/10.3138/jvme.30.4.344

30. Tella, S. (2003) M-learning-Cybertextual Traveling or a Herald of Post-Modern Education? In: Kynäslahti, H. and Seppälä, P. (eds.) Mobile Learning Helsinki. Helsinki: IT Press, pp. 7-21.

31. Trace, C. Baillie, S. and Short N. (2012) Development and Preliminary Evaluation of Student-Authored Electronic Cases. Journal of Veterinary Medical Education, 39 (4), pp. 368-74.

http://dx.doi.org/10.3138/jvme.0212-017R

32. Traxler, J. (2007) Defining, Discussing, and Evaluating Mobile Learning: The Moving Finger Writes and Having Writ... . The International Review of Research in Open and Distributed Learning, 8 (2), pp. 1-12.

33. Traxler, J. (2010) Distance Education and Mobile Learning: Catching up, Taking Stock. Distance 
Education, 31 (2), pp. 129-38. http://dx.doi.org/10.1080/01587919.2010.503362

34. Traxler, J. (2012) Sustaining Mobile Learning and its Institutions. In: Parsons D, ed. Refining Current Practices in mobile and Blended Learning: New Applications. Melbourne: Routledge, pp. 2-8.

35. Valliyate, M. Robinson, NG. and Goodman, JR. (2012) Current Concepts in Simulation and Other Alternatives for Veterinary Education: A Review. Veterinarni Medicina, 57 (7), pp. 325-37.

36. Wallace, S. Clark, M. and White, J. (2012) 'It's on My iPhone': Attitudes to the Use of Mobile Computing Devices in Medical Education, a Mixed-Methods Study. BMJ Open 2 (4). http://dx.doi.org/10.1136/bmjopen-2012-001099

37. Wasko, MM. and Faraj, S. (2005). Why Should I Share? Examining Social Capital and Knowledge Contribution in Electronic Networks of Practice. MIS Quarterly, 29 (1), pp. 35-57.

38. Wolff, C. (2006) Information Retrieval is for Everybody - Beobachtungen und Thesen. In: Schaaf MuA, KD, ed. Lernen, Wissensentdeckung und Adaptivität - LWA / Workshop Information Retrieval der GI FGIR 2006 Hildesheimer Informatik-Berichte. Hildesheim, Universität Hildesheim, pp. 102-7.

39. Wu, TT. (2014) Using Smart Mobile Devices in Social-Network-Based Health Education Practice: A Learning Behavior Analysis. Nurse Education Today, 34 (6), pp. 958-63.

http://dx.doi.org/10.1016/i.nedt.2014.01.013

TABLES \& CHARTS

Table 1: Use of mobile devices and operating systems by third year veterinary students $(n=124)$

\begin{tabular}{lll}
\hline Use of mobile devices & $\mathrm{n}$ & $\%^{2}$ \\
\hline Smartphone & 108 & 84.7 \\
Smartphone and other electronic devices $^{1}$ & 47 & 37.9 \\
Conventional cell phone $_{\text {Conventional cell phone and other electronic devices }}{ }^{1}$ & 18 & 14.5 \\
Co & 9 & 7.2
\end{tabular}

\begin{tabular}{lll}
\hline Operating systems & $\mathrm{n}$ & $\%^{2}$ \\
\hline Android & 55 & 44.1 \\
IOS & 51 & 41.1 \\
Android and Windows & 15 & 12.1 \\
IOS and Windows & 12 & 9.7 \\
\hline
\end{tabular}

${ }^{1}$ other electronic devices: tablet, E-book-reader, laptop

${ }^{2}$ multiple selection was possible; not all questions were answered by all participants

Table 2: Use of social media by third year veterinary students $(n=124)$

\begin{tabular}{llllll}
\hline & Facebook $^{1}$ & WhatsApp $^{1}$ & Telegram $^{1}$ & Skype $^{1}$ & Twitter $^{1}$ \\
\hline Often & $70.2 \%$ & $74.2 \%$ & $1.6 \%$ & $12.9 \%$ & $0.8 \%$ \\
Occasional & $18.5 \%$ & $2.4 \%$ & $8.9 \%$ & $53.2 \%$ & $0.0 \%$ \\
Never & $8.9 \%$ & $19.4 \%$ & $83.1 \%$ & $31.5 \%$ & $92.7 \%$ \\
\hline
\end{tabular}

${ }^{1}$ multiple selection was possible; not all questions were answered by all participants 
Fig. 1. Questionnaire to assess the use of mobile devices by German veterinary students

Personal data:

Age: Semester: Sex:

Please tick the boxes

1. Which operating system(s) do you use?
$\square$ Conventional cell phone
$\square$ Smartphone
$\square$ Tablet
$\square$ E-Book-Reader
$\square$ Other

2. Which operating system do you use?
$\square$ Android
$\square$ IOS (Apple)
BlackBerry
$\square$ Windows
$\square$ Other

3. Do you have an Internet flat rate for your mobile device?

$\square$ yes

4. Which online services do you use via your mobile device? often occasionally never often occasionally never
Google
Dictionary
Wikipedia

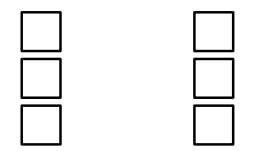
Google Maps
Blackboard
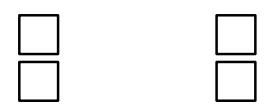
$\square$ Other

5. Do you have a QR code reader?
$\square$ yes
$\square$ no

...if yes, how often do you use a QR code?

often occasionally never


6. Which social media do you use? Please indicate for all that apply!

often occasionally never often occasionally never

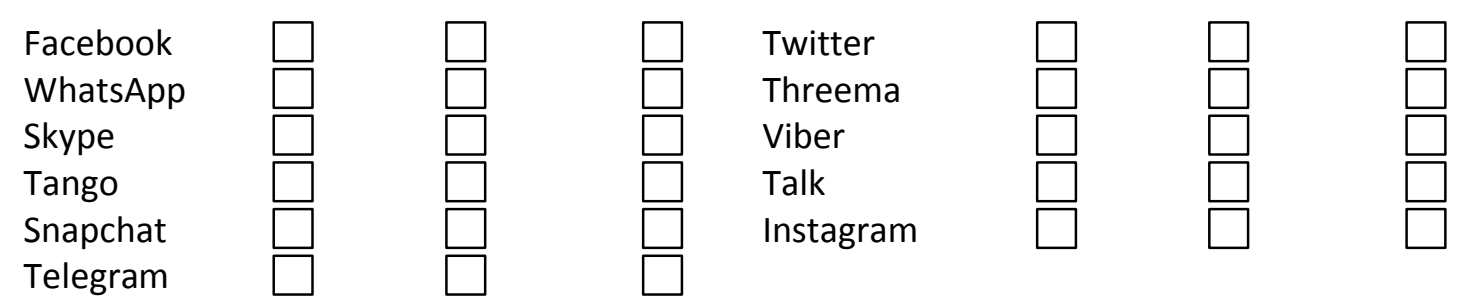

Other

7. How much time per day do you spend online with your mobile device(s??

Less than

$1 \mathrm{~h}$

$1-2 h$

$2-4 h$

more than
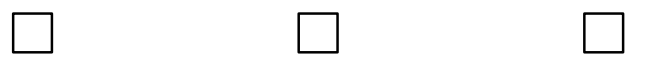

$4 \mathrm{~h}$

8. In average, after what time interval do you answer a received message?

Immediately within 5 min when I have time

9. What is your favorite App?

10. Which veterinary online tools would you like to have? 


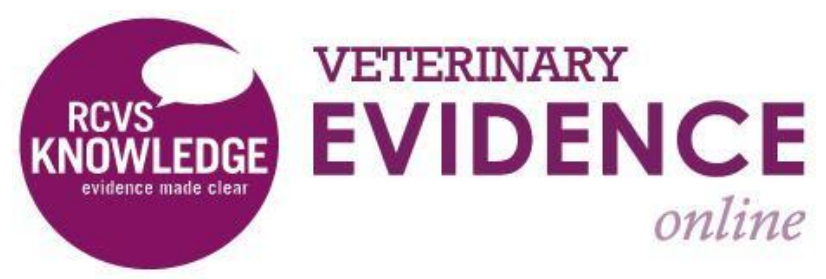

\section{Intellectual Property Rights}

Authors of Articles submitted to RCVS Knowledge for publication will retain copyright in their work, but will be required to grant to RCVS Knowledge an exclusive license of the rights of copyright in the materials including but not limited to the right to publish, re-publish, transmit, sell, distribute and otherwise use the materials in all languages and all media throughout the world, and to license or permit others to do so.

Authors will be required to complete a license for publication form, and will in return retain certain rights as detailed on the form.

Veterinary Evidence and EBVM Network are RCVS Knowledge initiatives. For more information please contact us at editor@veterinaryevidence.org.

RCVS Knowledge is the independent charity associated with the Royal College of Veterinary Surgeons (RCVS). Our ambition is to become a global intermediary for evidence based veterinary knowledge by providing access to information that is of immediate value to practicing veterinary professionals and directly contributes to evidence based clinical decision-making.

www.veterinaryevidence.org

RCVS Knowledge is a registered Charity No. 230886. Registered as a Company limited by guarantee in England and Wales No. 598443.

Registered Office:

Belgravia House

62-64 Horseferry Road

London SW1P 2AF

(c) (†)

This work is licensed under a Creative Commons Attribution 4.0 International License. 